\title{
Francesismo ou nacionalismo? Dilemas do modernismo brasileiro nas cartas dos anos 1920
}

\author{
[ Love of France or nationalism? Dilemmas of Brazilian \\ modernism in the literary correspondence of the I920s
}

José Luís Jobim ${ }^{\mathrm{I}}$

\begin{abstract}
RESUMO - Neste trabalho, pretendemos explorar as questões das referências francesa e europeia, principalmente em cartas de Carlos Drummond de Andrade, Mário de Andrade e Manuel Bandeira, nos anos I920, chamando a atenção para os imaginários construídos com as noções de "aqui" (Minas, São Paulo, Rio, Brasil, América Latina) e "lá" (França, Europa), na palavra que circula entre e através desses autores. Também formularemos uma hipótese sobre crítica literária "interna" e "externa”, envolvendo essa correspondência. PALAVRAS-CHAVE . Correspondência; Mário de Andrade; Carlos Drummond de Andrade; Manuel Bandeira; Modernismo brasileiro; francesismo/
\end{abstract}

nacionalismo. ABSTRACT $\cdot$ In this essay we intend to explore the French and European references, principally in the correspondence between Carlos Drummond de Andrade, Mário de Andrade e Manuel Bandeira, in the I920s, focusing on the imaginaries concocted with the ideas of "here" (Minas Gerais, São Paulo, Rio de Janeiro, Brasil, América Latina) and “there" (France, Europe). We will also formulate a hypothesis about "internal" and "external" literary criticism, involving this correspondence. KEYWORDS - Correspondence; Mário de Andrade; Carlos Drummond de Andrade; Manuel Bandeira; Brazilian modernism; love of France/ nationalism.

Recebido em I2 de setembro de 2017 Aprovado em II de outubro de 2017

JOBIM, José Luís. Francesismo ou nacionalismo? Dilemas do modernismo brasileiro nas cartas dos anos I920. Revista do Instituto de Estudos Brasileiros, Brasil, n. 68, p. 208-226, dez. 2017.

DOI: http://dx.doi.org/IO.II6o6/issn.23I6-90IX.voi68p208-226

I Universidade Federal Fluminense (UFF, Niterói, RJ, Brasil). 
Na primeira carta de Mário de Andrade a Carlos Drummond de Andrade (Io/II/I924), ele escreve: "Você é uma sólida inteligência e já muito bem mobiliada... à francesa"2. Em resposta, Drummond atribui a si próprio o dilema que não era só seu: sentir-se obrigado a manifestar em sua obra um nacionalismo que, ao mesmo tempo, apresentava como necessário e como duvidoso. Tudo isso sempre à sombra de sua francofilia confessa - que, de fato, remete mais a Paris do que à França como um todo:

Não sou ainda suficientemente brasileiro. Mas, às vezes, me pergunto se vale a pena sê-lo. Pessoalmente, acho lastimável essa história de nascer entre paisagens incultas e sob céus pouco civilizados. Tenho uma estima bem medíocre pelo panorama brasileiro. Sou um mau cidadão, confesso. É que nasci em Minas, quando deveria nascer (não veja cabotinismo nessa confissão, peço-lhe!) em Paris³.

Neste trabalho, pretendemos explorar as questões das referências francesa e europeia, principalmente em cartas de Carlos Drummond de Andrade, Mário de Andrade e Manuel Bandeira, nos anos I920, chamando a atenção para os imaginários construídos com as noções de "aqui” (Minas, São Paulo, Rio, Brasil, América Latina) e "lá" (França, Europa), na palavra que circula entre e através desses autores. Ao longo do trabalho a ser elaborado, procurar-se-á elaborar respostas possíveis à pergunta: “No seio dos diálogos interculturais, que palavras, que caminhos, que imagens emergem dessas diferentes representações de aqui e lá?”.

2 Carta de Mário de Andrade a Carlos Drummond de Andrade, Io de novembro de I924, apud SANTIAGO, Silviano (Org.). Carlos e Mário. Correspondência completa entre Carlos Drummond de Andrade e Mário de Andrade. Rio de Janeiro: Bem-te-vi, 2002, p. 50.

3 Carta de Carlos Drummond de Andrade a Mário de Andrade, 22 de novembro de I924, apud SANTIAGO, Silviano (Org.), op. cit. p. 56. 


\section{França e América Latina}

Não é novidade dizer que, a partir do século XIX, o Brasil, no âmbito da cultura francesa, também faz parte de um suposto mapa da "latinidade", dentro do qual a França teria um papel de centro disseminador, mas a própria designação da Ibero-América como "América Latina" merece ser vista como parte de um quadro maior, como veremos a seguir.

América Latina é uma designação comprovadamente anterior ao século XX, e Paulo Moreira já apontou para uma das hipóteses sobre sua origem, que remete a sentidos completamente opostos àqueles anti-imperialistas que vai adquirir a partir do fim da Segunda Guerra Mundial. Esta hipótese, segundo Moreira, associaria aquela expressão ao panlatinismo francês do século XIX - que teria sido uma tentativa por parte de imperialistas franceses de dar um verniz culturalista às rivalidades com Inglaterra, Prússia e Rússia, acentuando um contraste entre as culturas europeias falantes de línguas românicas e praticantes do catolicismo e as culturas do norte germânico e/ou do leste eslavo:

Sua aparição em matéria impressa praticamente coincide com a malfadada invasão francesa do México entre I864 e I867, que levou à breve condução do arquiduque austríaco Maximiliano (parente do monarca brasileiro) ao posto de imperador daquele país. Essa possível primeira configuração do termo América Latina seria, portanto, expressão do agressivo imperialismo europeu do século XIX, e há quem defenda que essa filiação eurocêntrica justifique uma completa rejeição do termo nos dias de hoje4.

Moreira considera irônico atribuir ao economista francês Michel Chevalier (I806-I879) a criação da expressão América Latina, em livro sobre os Estados Unidos publicado em I836 (Lettres sur l'Amerique du Nord) e traduzido três anos depois para o inglês a partir da terceira edição francesa, com o título de Society, manners and politics in the United States: being a series of letters on North America. Afinal, Lettres sur l'Amerique du Nord tinha sido escrito por um autor francês "preocupado em aprender sobre um regime liberal, estável, moderado, próspero e eficiente que servisse de espelho para o juste milieu que Louis Phillipe (I830-I848) pregava como solução para os conflitos que sacudiam a França desde I789”.

Baseados em supostas características inatas das populações "latinas" e "anglo-saxônicas", encontram-se já em Chevalier numerosos argumentos que, no ensaísmo sul-americano, vão ser utilizados para atribuir certo materialismo e pragmatismo aos anglo-saxões, em oposição a uma suposta espiritualidade latina, mas Paulo Moreira chama a atenção do leitor para o fato de que Chevalier era um admirador do empreendedorismo norte-americano:

\footnotetext{
4 MOREIRA, Paulo Vaz. Quando a América se torna pela primeira vez latina. In: JOBIM, José Luís. A circulação literária e cultural. Oxford: Peter Lang, 20I7, p. I53-I80.

5 Ibidem, p. 156.
} 
Com tom de admiração Chevalier nos fala de ianques de Massachusetts e Connecticut, a quem ele chama de "Mecânicos de alma”, inventando incansavelmente novas máquinas ou ferramentas enquanto os franceses se ocupam com a composição de "um vaudeville, um romanceiro ou uma constituição republicana ou monárquica". ${ }^{26}$ "Imbuídos de protestantismo até a medula dos ossos", ${ }^{27}$ os anglo-saxões americanos se concentram na produção de riqueza e não se importam em viver num estado de relativo isolamento que os franceses, "eminentemente sociais", não suportam, já que "reservam suas afeições e simpatias para os objetos vivos" 28 e preferem "a segurança de um amigo ou a felicidade de uma amante" ao "sucesso de uma manufatura". ${ }^{29}$

\footnotetext{
${ }^{26}$ No original, “Chez nous, il n'y a pas d'élève des hautes écoles qui n'ait fait son vaudeville, son roman ou sa constitution monarchique ou républicaine. Il n’y a pas de paysan du Connecticut ou du Massachussets qui n’ait inventé sa machine" [...].

${ }^{27}$ No original: "imbu de protestantisme jusqu’à la moelle des os” [...].

${ }^{28}$ No original, "Éminemment social [...] réserve ses affections et ses sympathies pour ce qui est vivant” [...].

${ }^{29}$ Em francês, "le salut d'un ami ou le Bonheur d'une maîtresse [...] le success d'une manufacture" [...] ${ }^{6}$.
}

No Brasil, nos anos 1920, a ideia de latinidade não era muito popular entre os modernistas. Ronald de Carvalho, em carta de I5 de maio de I926, dirigida a Prudente de Moraes, neto, diz que "[...] o latino europeu é um elemento do americano, e não é todo o americano"? E acrescenta:

Se você caracteriza o latino europeu pela cultura, todos nós, meu querido Prudente, somos latinos europeus, somos diáteses de um meio latino europeu. Por mais cultos, porém, que sejamos, a nossa cultura não nos libertará de um certo sentimento de humanidade americana, a que estamos sujeitos pelas próprias fatalidades de nossa índole. Destarte, como pode você determinar seguramente, com todo o sentido lógico da sua inteligência, que a minha poesia não é brasileira e o meu sentimento não é americano? Impossível, meu caro Prudente ${ }^{8}$.

Claro, se mudarmos o foco, passando da designação mais ampla (América Latina) para uma mais restrita (a de cada nação desta suposta América Latina), é interessante lembrar que a própria definição do que é uma nação foi objeto de muita discussão no século XIX. Não vou aqui falar mais longamente sobre isso para não me distanciar do foco deste meu trabalho, mas quero lembrar um dos textos mais famosos sobre o assunto - originalmente uma conferência, pronunciada na Sorbonne, em II de março de I882, pelo grande maître à penser francês dessa época Ernest Renan (I823-I892), intitulada Qu'est-ce qu'une nation?.

Nesse texto, ao defender uma concepção de nação multiétnica e plurilinguística em parte dando seguimento à sua contestação dos argumentos alemães usados para

6 Ibidem, p. I64-I65.

7 Carta de Ronald de Carvalho a Prudente de Moraes, neto, I5 de maio de I926, apud KOIFMAN, Georgina.

Cartas de Mário de Andrade a Prudente de Moraes, neto (I924/36). Rio de Janeiro: Nova Fronteira, I985, p. 206.

8 Ibidem. 
justificar a anexação da Alsácia-Lorena, que incluíam ideias sobre homogeneidade étnica e linguística -, Renan também defende uma nação legitimada pela participação de seus cidadãos na própria configuração da nacionalidade. No entanto, embora adotando um tom de validação universal dos princípios que fundamentam a nação, também não perde a oportunidade de atribuir uma paternidade francesa aos supostos princípios universais que apresenta: "C'est la gloire de la France d'avoir, par la Révolution française, proclamé qu'une nation existe par elle-même. Nous ne devons pas trouver mauvais qu'on nous imite. Le principe des nations est le nôtre"?.

Do ponto de vista literário, não foi apenas o Brasil que teve a França - ou, para ser mais específico, Paris - como referência privilegiada no século XIX. O nicaraguense Rubén Darío (I867-I9I6), grande nome internacional do modernismo hispano-americano ${ }^{\mathrm{Io}}$, pode servir aqui como exemplo. Em uma crônica publicada no jornal argentino La Nación, na data comemorativa da queda da bastilha, em I4 de julho de I898, significativamente intitulada "La fiesta de Francia", respondendo à pergunta sobre qual é o segredo de a França ser amada por todos os corações e saudada por todas as almas, ele "encontra a resposta em sua filiação à genealogia da cultura moderna que data do mundo clássico"ז. Nas palavras de Darío: "A áurea Paris derrama sobre o orbe o antigo reflexo que brotava da Atenas marmórea [...]. O idioma da França é o novo latim dos sacerdotes ideais e seletos e nele ressoam harmoniosamente as saudações à imortal Esperança e ao Ideal eterno”².

Pablo Rocca nos informou que Rubén Darío, em duas ocasiões, I906 e I9I2, também esteve no "Brasil de fuego", como o chamou no poema que dedicou a Machado de Assis, o literato mais prestigioso do Brasil no início do século XX, fundador e presidente da Academia Brasileira de Letras. Segundo Rocca:

[Na viagem de I9I2, Darío] capitaliza os vínculos de sua estadia anterior e recebe uma homenagem na Academia Brasileira de Letras, onde José Veríssimo lhe oferece um discurso de boas-vindas. Veríssimo conhecia a obra de Darío, ainda que não a tivesse em grande estima, já que em um artigo que recolheu em Homens e coisas estrangeiras (I9IO), anotava que Darío “de hispano-americano apenas terá o sangue, $o$ nome, o nascimento", porque em sua opinião é "um francês, um espanhol, se não de Paris,

9 RENAN, Ernest. Qu'est-ce qu'une nation?. Paris: Calmann Lévy, I882. Disponível em: <fr.wikisource.org/wiki/ Qu\%E2\%80\%99est-ce_qu\%E2\%80\%99une_nation_\%3F>. Acesso em: 24 jul. 2017.

Io Como se sabe, "modernista”, na América hispânica, não corresponde a "modernista” no Brasil. Na América hispânica, "modernista” é o equivalente a "parnasiano” e a "simbolista” na literatura brasileira.

II SISKIND, Mariano. Dislocating France; world literature, global modernism and cosmopolitan distance. Journal of World Literature, v. 2, issue I, p. 47-62, 20I7, p. 54 (tradução nossa).

I2 DARÍO, Rubén apud SISKIND, Mariano, op. cit., p. 54 (tradução nossa). 
dos cenáculos do Quartier Latin, discípulo imediato e imitador complacente dos poetas que escandalizaram o burguês por pouco tempo e logo desapareceram”’3.

Assim, por tudo o que foi dito até aqui, pode-se observar que o gesto de Carlos Drummond de Andrade, na carta que citamos, declarando que devia ter nascido em Paris, em vez de em Minas Gerais, está longe de ser um fato isolado, inserindo-se em um contexto maior, que retrocede pelo menos até o século XIX. No entanto, para compreendermos melhor o sentido da manifestação de Drummond, na carta a Mário de Andrade, precisamos também falar sobre o papel que a correspondência entre autores modernistas brasileiros tinha no sistema literário de que faziam parte.

\section{A CORRESPONDÊNCIA NO MODERNISMO BRASILEIRO}

Entre outras coisas, a publicação de muitos volumes de correspondência de autores modernistas tem demonstrado que, no sistema literário modernista brasileiro, havia pelo menos duas modalidades de crítica literária: uma externa e pública, por assim dizer, praticada em jornais e revistas; outra interna e privada, praticada entre literatos. A primeira, mais visível, guarda uma relação mais aparente com o que se faz em outros sistemas literários ocidentais. A segunda, invisível publicamente, foi muito mais importante no que diz respeito aos produtos finais de que hoje dispomos para analisar: as obras literárias dos missivistas. Por quê?

Porque nessas cartas os autores pediam opinião sobre os textos que estavam naquele momento elaborando, e recebiam de volta um tipo de crítica que atuava sobre seu trabalho in progress, gerando pelo menos três situações. Ou o autor modificava seu texto, acolhendo as sugestões de seu "crítico"; ou ele fazia outra versão, que não correspondia nem à anterior, nem à sugerida por seu "crítico"; ou ele mantinha sua versão (apesar da "crítica") e, nesse caso, essa versão não era a mesma para ele, porque a manutenção da versão anterior agora era fruto de uma reflexão desenvolvida a partir de uma opinião contrária - e, por consequência, a conclusão pela reiteração da forma anterior era marcada por uma decisão que considerou impertinentes as objeções feitas àquela forma.

Aqui é importante assinalar também o efeito mais radical daquela crítica interna e privada, praticada entre literatos: a exclusão pura e simples de textos quando o criticado concorda com as observações negativas feitas pelo crítico, ou quando as restrições do crítico o levam a repensar o que fez e chegar à conclusão de que determinado texto não merece ser publicado, por alguma razão. Esse efeito só pode ser comprovado através das cartas, porque ausências, obviamente, não podem ser observadas em livros publicados. Só se percebe o efeito da crítica interna quando, ao ler a correspondência, verifica-se a existência de um texto remetido por um escritor

I3 ROCCA, Pablo. Os contrabandistas: tensões e fundamentos da primeira circulação do Machado de Assis no Rio da Prata. In: SECCHIN, Antonio Carlos; BASTOS, Dau; JOBIM, José Luís (Org.). Machado de Assis: novas perspectivas sobre a obra e o autor no centenário de sua morte. Niterói: Editora da Universidade Federal Fluminense; Rio de Janeiro: De Letras, 2008, p. I4I-I60. p. I49 (grifos nossos). 
a um destinatário (solicitando sua opinião). Quando a opinião do destinatário é negativa, podemos interpretar a ausência do texto criticado no livro posterior como efeito da crítica interna feita àquele texto, que gerou a sua exclusão da publicação.

O resultado dessa crítica interna pode ser aferido, por exemplo, no livro Alguma poesia, lançado em I930, estreia literária de Carlos Drummond de Andrade, cujos originais foram objeto de intensa discussão epistolar do autor com Mário de Andrade. A maior parte dos poemas desse livro, anteriormente intitulado "Minha terra tem palmeiras", fazia parte de um "caderno de versos" enviado por Carlos para Mário em 3 de junho de I926, mobilizando a correspondência dos dois autores durante três meses. Esse volume de 63 poemas hoje faz parte do Fundo Mário de Andrade do Arquivo do Instituto de Estudos Brasileiros da Universidade de São Paulo, é dedicado a Mário e conclama a generosidade do autor paulista em sua avaliação poética:

A primeira parte é só por amizade que te comunico. Sei que são versos inferiores, até penumbristas; só valeu como documentação. Tem muita lagrimazinha besta e muito estrepe sentimental nesses papéis. Você dê o devido desconto e me queira sempre bem. Obrigado pelas boas, pelas grandes palavras da última carta. Que consolo ter um amigo batuta como você! A gente adquire confiança na vida. Eu sarei do meu último ataque de desânimo só com a sua carta ${ }^{\mathrm{I} 4}$.

O caderno é avaliado por Mário de Andrade no final de sua carta, fazendo uma leitura dos poemas sobretudo pelo viés de seu gosto pessoal, sem recorrer a algum critério externo específico. Como de costume, Mário expressa sua predileção principalmente com adjetivos (horrível, vulgarzinho, sensualíssimo, lindo, gostoso, pesado, ruim, delícia, perigoso e decadente - entre muitos outros), usados para explicitar sua desaprovação ou entusiasmo pelo uso que Carlos faz do léxico, ordem gramatical indireta nos versos, ritmo, clareza e recursos retóricos, entre muitos outros. Mário também recomenda a Carlos excluir os galicismos do texto, um de seus "horrores", como no poema "Sensual", porque o "desagrada" ᄁ. . Mas qual o contexto dessa rejeição a galicismos, ou seja, a palavras ou expressões vindas da língua francesa? Abro aqui parênteses para explicar o contexto histórico do século XIX que iniciou a reação contra os galicismos, não por acaso na época das invasões napoleônicas.

Começo a explicação informando que foi naquele século que se editou em Portugal - Glossário das palavras e frases da língua francesa, que por descuido, ignorância ou necessidade se tem introduzido na locução portuguesa moderna ${ }^{\text {I6 }}$. $\mathrm{O}$ assunto, inclusive com a introdução do termo galicismo com sentido pejorativo, foi proposto pela

I4 Carta de Carlos Drummond de Andrade a Mário de Andrade, 3 de junho de I926, apud SANTIAGO, Silviano (Org.), op. cit., p. 220.

I5 Carta de Mário de Andrade a Carlos Drummond de Andrade, Iำ de agosto de I926, apud SANTIAGO, Silviano (Org.), op. cit., p. 226-234.

I6 LUIZ, D. Fr. Francisco de S. Glossário das palavras e frases da língua francesa, que por descuido, ignorância ou necessidade se tem introduzido na locução portuguesa moderna; com o juízo crítico das que são adotáveis nela. Lisboa: Tipografia da Academia Real das Ciências, I827. Disponível em: <http://sebinaol.unior.it/sebina/repository/ catalogazione/documenti/Glossario\%2odas\%2opalavras\%20(397349).pdf $\rangle$. Acesso em: 24 jul. 2017. 
Academia Real das Ciências no programa de I8Io. A proposta era fazer um Glossário, ou catálogo de palavras e frases "[...] em que se mostre com toda a individuação as que são próprias da língua francesa, e que por descuido ou ignorância se tem introduzido na locução portuguesa moderna, contra o antigo e bom uso, e principalmente as que forem contra o gênio da nossa língua e como tais inadotáveis nela”77. Hoje, podemos perceber que, se foi importante ou necessário que aquele glossário fosse elaborado, isso significa que a presença de palavras francesas já era um fato notável então. A ideia, já presente no Glossário, de valorizar o cunho vernáculo das palavras, e rejeitar estrangeirismos, ao mesmo tempo que é adotada por Mário ao criticar os galicismos de Drummond, também é contestada por outro poeta importante do círculo modernista, Manuel Bandeira, no poema "Poética", publicado em Libertinagem (I930), livro que reúne sua produção literária entre I924 e I930: "Estou farto do lirismo que para e vai averiguar no dicionário o cunho vernáculo de um vocábulo”s8.

De fato, em carta de I5 de março de I929, Bandeira pede a opinião de Mário sobre o título da coletânea de poemas que vai publicar no ano seguinte, expressando dúvidas sobre se deveria dar-lhe o mesmo título do livro do escritor francês Louis Aragon:

O "libertino" me agrada extraordinariamente e pouco me importa que me tomem por outra coisa. Me lembrei outro dia desse título Outra coisa. O Alcântara achou muito bom. Que acha? Eu prefiro este que Rodrigo propôs: Libertinagem apesar de haver o Le libertinage de Aragon, estou tentadíssimo ${ }^{\mathrm{I}}$.

No caso de Mário, causa estranhamento a sua condenação do uso de galicismos, pelo menos por duas razões: I) ele não se alinhava com os "puristas" da época, que imaginavam a língua como uma herança lusitana homogênea e pura, e viam as supostas ameaças àquela herança como "erros" ou "vícios" - por exemplo: acréscimos lexicais vindos de outras línguas ou até de outros países em que também se usava a "mesma" língua de Portugal, como o Brasil; 2) ele era um leitor habitual de obras francesas, como provam o seu acervo, hoje sob a guarda do Instituto de Estudos Brasileiros da Universidade de São Paulo, e a correspondência com escritores de sua época. Na correspondência com Manuel Bandeira, o escritor pernambucano usa regularmente termos em francês (o que, evidentemente, significa que ele presume que o destinatário das cartas, Mário de Andrade, conheça o idioma...), e dá conselhos a Mário para que, na sua obra, use as palavras francesas com a grafia original: "Ah, escreva as palavras estrangeiras com a grafia de origem! Afinal nem sempre estão aportuguesadas. Há transcrições impossíveis. Pierrot parece estilo colonial com motivos do renascimento francês primitivo! E depois até os negros dizem direito chauffeur"

I7 Ibidem, p. V-VI.

I8 BANDEIRA, Manuel. Poesia e prosa. V. I. Rio de Janeiro: José Aguilar, I958, p. I88.

I9 Carta de Manuel Bandeira a Mário de Andrade, I5 de março de I929, apud MORAES, Marcos Antonio de (Org.). Correspondência - Mário de Andrade e Manuel Bandeira. São Paulo: Editora da Universidade de São Paulo, 2000, p. 4I5.

20 BANDEIRA, Manuel, op. cit., p. I32. 
Assim, considerando que mesmo o autor do Glossário oitocentista, Francisco de S. Luiz - o qual considerava “[...] serem sobremaneira numerosos os termos e expressões francesas com que se acha desfigurada a natural formosura de nossa linguagem"2I - , aceitava algumas incorporações lexicais, sob certas condições ${ }^{22}$, não faria sentido que um autor brasileiro modernista, no século seguinte ao daquele Glossário, recusasse o uso de galicismos, em nome de uma suposta "natural formosura de nossa linguagem", especialmente considerando que Mário estava a par das discussões linguísticas que, desde o século XIX, opuseram escritores e gramáticos dos dois lados do Atlântico, na discussão sobre o que, afinal, deveria ser a "nossa linguagem" ${ }^{33}$. Acho mais adequado, portanto, dizer que Mário, ao mesmo tempo que pagava certo tributo a algumas ideias linguísticas anteriores - das quais possivelmente não teria consciência plena - estava engajado em um projeto de "brasileirização" da língua portuguesa, que incluía, entre outras coisas, a colocação em xeque dos "estrangeirismos" em geral (e, por consequência, dos "galicismos" em particular) e a tentativa de produzir uma ortografia alternativa, bem como de incorporar contribuições lexicais de várias regiões do Brasil. Esse projeto está claramente configurado em seu poema "Lundu do escritor difícil", escrito em I92724, no qual ele deixa clara a intenção de misturar elementos provindos de diversas regiões do país: "Misturo tudo num saco,/ Mas gaúcho maranhense/ Que para no Mato Grosso,/ Bate este angu de caroço". E Mário deixa também clara a ligação que faz entre o galicismo e a imitação acrítica do estrangeiro: "Você sabe o francês 'singe'/ Mas não sabe o que é guariba?/ - Pois é macaco, seu mano,/ Que só sabe o que é da estranja"25. Em português, como sabemos, a expressão "macaco de imitação" designa, entre outras coisas, a pessoa que copia mecanicamente ações e comportamentos de outrem; portanto, quando Mário diz que a pessoa que só conhece o vocábulo francês, mas não o nacional, é "macaco de imitação", isso tem uma semelhança com as "consciências enlatadas", que aparecem no Manifesto antropófago, publicado em I928 por Oswald de Andrade, como veremos adiante. Além de tudo o que já dissemos, é importante dizer que Mário não condenava

2I LUIZ, D. Fr. Francisco de S., op. cit., p. V-VI.

22 "O juízo que fazemos sobre cada palavra ou frase, a respeito de se poder adotar, ou não, na nossa língua, não o declaramos sem algum receio de errar [...]. Em geral tivemos sempre diante dos olhos esta regra: 'que sendo o vocábulo de boa origem, derivado conforme a analogia, e ao mesmo tempo expressivo, e harmônico, se podia adotar e trazer à nossa língua, ainda quando nesta houvesse algum sinônimo, que exprimisse o mesmo conceito'; porque estamos persuadidos, que convém a cada idioma ter não só vocábulos correspondentes a cada ideia, mas ainda variedade deles com o mesmo significado; para que o douto e avisado escritor possa escolher a seu arbítrio, segundo a natureza e qualidades de sua composição, evitando a fastidiosa repetição dos mesmos termos, e a cansada uniformidade da locução e estilo.” Ibidem, p. VI.

23 Para uma visão mais abrangente e detalhada dessa questão, ver: MARIANI, Bethania \& JOBIM, José Luís. National language and post-colonial literature in Brazil. Revista da ANPOLL, v. I, n. 20, 2006, p. II-36. Disponível em: <revistadaanpoll.emnuvens.com.br/revista/article/view/473/482〉. Acesso em: 24 jul. 2017.

24 Para a datação do ano do poema, ver a informação de Mário de Andrade, em carta de 6 de abril de I927 a Manuel Bandeira, em: MORAES, Marcos Antonio de, op. cit., p. 34I.

25 ANDRADE, Mário de. Poesias completas. V. 2. São Paulo: Martins, I980, p. 242. 
em Carlos Drummond de Andrade a leitura de autores franceses - até porque Mário também os lia. Condenava, isto sim, o que chamava de "moléstia de $\mathrm{Nabuco"}^{26} \mathrm{em}$ Drummond. Mário definiu essa "moléstia" em uma entrevista ao jornal A noite, publicada em I2 de dezembro de I925: "Moléstia de Nabuco é isso de vocês andarem sentindo saudade do cais do Sena em plena Quinta da Boa Vista [...]"27.

Ao comentar, em carta a Prudente de Moraes, neto, de 25 de novembro de I927, 0 surrealismo francês no Brasil (que ele chama de sobrerrealismo), Mário deixa clara sua posição sobre a França:

O sobrerrealismo é uma arte quintessenciada que me atrairia fatalmente se eu não me tivesse dado uma função de acordo mais com a civilização e o lugar em que vivo. Porque incontestavelmente a civilização em que a gente vive aqui no Brasil não é a mesma dos franceses [,] não acha mesmo? Não discuto se é melhor se é pior e muito menos por mais problemático se é de fato a civilização nova que está principiando. Não discuto porque acho pueril discutir coisas pras quais nos faltam dados suficientes que só virão com os anos. Também não vá imaginar que estou glosando essa história boba do "homem bárbaro". Não acho que somos bárbaros. Mas incontestavelmente me parece que não estamos naquele momento de fadiga em que está a arte francesa com séculos de tradição organizada nacionalmente, atrás dela. E tendo dado séculos de escritores magníficos. Você sabe tão bem que na França hoje a língua chegou a um tal estado de perfeição dogmática que toda a gente escreve bem. [...] Considero o sobrerrealismo a consequência lógica e a quintessência de arte dum país que nem a França. No Brasil acho que no momento atual, pros que estão de deveras acomodados dentro da nossa realidade, ele não adianta nada ${ }^{28}$.

A carta a Prudente era para comentar a atribuição de caráter "sobrerrealista" a textos recém-publicados, e está dentro da lógica sistêmica que já apontamos antes. No entanto, o efeito, no sistema literário modernista, daquilo que designamos como

26 Tratava-se de uma designação irônica, invocando o nome de Joaquim Nabuco, que em seu livro Minha formação escreveu: “Um brilhante frequentador da Revista Brasileira, que possui entre outras qualidades talvez a mais preciosa de todas, uma boa quantidade do fluido simpático, admira-se dessa minha afinidade francesa; com efeito, não revelo nenhum segredo, dizendo que insensivelmente a minha frase é uma tradução livre, e que nada seria mais fácil do que vertê-la outra vez para o francês do qual ela procede. O que me admira é que o mesmo não aconteça a todos os que têm lido tanto em francês como eu, mais do que eu, e cuja vida intelectual tem sido assim em sua parte principal, isto é, em toda a sua função aquisitiva, francesa. E talvez que eles têm uma força de assimilação maior do que a minha - ou que eu tenho mais desenvolvida do que eles a faculdade imitativa? Não sei; mas essa suscetibilidade à influência francesa parece natural em espíritos que recebem quase tudo em francês e que têm horror à tradução; o purismo português, esse, sim, é que, até tornar-se uma segunda natureza literária, exige uma constante vigilância, a retificação exata de todo o trabalho de aquisição intelectual”. NABUCO, Joaquim. Minha formação. [I900], p. 25-26. Disponível em: <www. iphi.org.br/sites/filosofia_brasil/Joaquim_Nabuco_-_Minha_Forma\%C3\%A7ao.pdf $>$. Acesso em: 25 jul. 2017.

27 Mário de Andrade em entrevista ao jornal A noite apud KOIFMAN, Georgina, op. cit., p. I48.

28 Carta de Mário de Andrade a Prudente de Moraes, neto, 25 de novembro de I927, apud KOIFMAN, Georgina, op. cit., p. 247-248. 
crítica interna e privada, presente nas cartas, também é derivado da posição relativa dos missivistas entre si. Nas cartas entre Mário de Andrade e Manuel Bandeira, Mário coloca Bandeira na posição de mentor. Nas cartas entre Carlos Drummond de Andrade e Mário de Andrade, Carlos coloca Mário na posição de mentor. Embora os que são colocados na posição de mentores questionem essa atribuição, e também submetam seus textos aos parceiros, a assimetria nas posições é elemento importante a ser considerado. Bandeira reclama de Mário, em I924, que o poeta paulista não tenha feito uma crítica detalhada de seu livro Carnaval:

Mário,

Antes de entregar os meus versos à tipografia, mandei-os a você, pedindo-lhe que os criticasse: o meu desejo era que você fizesse com eles o que eu a seu pedido, faço com os seus: uma espinafração isenta de qualquer medo de magoar ou melindrar - crítica de sala de jantar de família carioca, de pijama e chinelo sem meia. Você tirou o corpo fora e limitou-se a aconselhar a supressão de um soneto. Se você tivesse me dado outros conselhos, o meu livro sairia mais magro porém certamente mais belo ${ }^{29}$.

Mário sentiu implícita nessa carta de Bandeira uma acusação de que teria deixado de fazer a crítica interna, ou seja, teria deixado de elaborar as ressalvas e observações no estágio de pré-publicação do livro (quando o autor ainda podia modificar a obra) para poder usar essas mesmas ressalvas e observações no estágio de pós-publicação do livro. Naquele sistema literário, isso seria algo equivalente a uma canalhice, razão pela qual Mário se apressa em tentar desmentir essa possibilidade:

Deus me livre, por exemplo, que você pense que ao ler teus originais eu tenha dito pra mim: "Não, isso eu vou guardar pra cascar na crítica de quando sair o livro". Isso eu era incapaz de fazer contigo e é pensamento intolerável pra mim que imagines sequer de leve eu tenha feito isso. Não fiz ${ }^{30}$.

A correspondência de Mário e seus parceiros modernistas já era considerada extremamente relevante muito antes de estar acessível ao público. Antonio Candido ${ }^{3 \mathrm{I}}$, em I946, já adiantava que essas cartas eram a parte mais importante de sua obra, e advertia que a escrita epistolar do autor de Macunaíma era volumosa. "Eu sofro de gigantismo epistolar”32, avisou o próprio Mário em sua primeira carta dirigida a Carlos, em novembro de I924.

No que diz respeito à relação com a Europa em geral e com a França em particular,

29 Carta de Manuel Bandeira a Mário de Andrade, I924, apud MORAES, Marcos Antonio de (Org.), op. cit., p. I65.

30 Carta de Mário de Andrade a Manuel Bandeira, 29 de dezembro de I924, apud MORAES, Marcos Antonio de (Org.), op. cit., p. I68.

3I CANDIDO, Antonio. Lembrança de Mário de Andrade. In: . O observador literário. (I⿳亠口冋 ed., I959). 3. ed. rev. e ampliada. Rio de Janeiro: Ouro Sobre Azul, 2004, p. 9I-95.

32 Carta de Mário de Andrade a Carlos Drummond de Andrade, Io de novembro de I924, apud SANTIAGO, Silviano (Org.), op. cit. p. 50. 
embora Drummond, nos anos I920, ainda expresse uma admiração irrestrita pelo que vinha de Paris, Mário de Andrade e Manuel Bandeira não têm a mesma atitude. Bandeira, que usa palavras e expressões francesas, bem como galicismos em sua correspondência - talvez até para implicar com Mário ${ }^{33}$-, publica poemas em francês e declara, em carta a Mário, datada de 3 de janeiro de I925:

Sou, de fato, de formação parnasiano-simbolista. Cheguei à feira modernista pelo expresso Verlaine-Rimbaud-Apollinaire. Mas chegado lá, não entrei. Fiquei sapeando de fora. É muito divertido e a gente tem a liberdade de mandar aquilo tudo se foder, sem precisar chorar o preço da entrada ${ }^{34}$.

De alguma maneira, Bandeira assume o fato de que a circulação da literatura francesa no Brasil (no caso dele, o expresso Verlaine-Rimbaud-Apollinaire) não significa que haverá uma reiteração do que se produziu na França, porque, nas novas condições contextuais, o autor brasileiro pode beneficiar-se do conhecimento daquela produção, mas, nas palavras de Manuel Bandeira, "tem a liberdade de mandar aquilo tudo se foder, sem precisar chorar o preço da entrada”. A possibilidade de escrever depois de ter lido autores e obras estrangeiros é vista como uma vantagem, já que se pode avaliar melhor o que teria dado certo ou não das práticas literárias anteriores. A ideia de que escrever depois de ter lido pode ser vantajoso, aliás, já existia na América Latina do século XIX. Em momento anterior, apresentamos um bom exemplo disso ${ }^{35}$, comentando o dilema do escritor e político argentino Domingo Faustino Sarmiento, durante seu exílio no Chile, na década de 40 do século XIX: como motivar os leitores do jornal local El Progreso, que ele havia fundado, se os jornais europeus e americanos também estavam disponíveis para aquele público? A resposta de Sarmiento foi que El Progreso era melhor do que os mais conhecidos jornais do mundo porque, sendo um dos últimos a serem publicados, podia selecionar o melhor entre tudo o que já havia sido publicado. Na verdade, este é um tema recorrente para a literatura e a cultura latino-americanas, tanto que aparece formulado de maneira muito sintética nos "poemínimos" do escritor mexicano Efraín Huerta, em um poema escrito em I969: "El que escribe al ultimo/ Escribe major"36.

Além disso, a metáfora utilizada por Bandeira, de chegar à feira, mas não entrar, de "sapear de fora" é significativa. Ele leu Verlaine-Rimbaud-Apollinaire, mas não reproduziu o que eles fizeram. Tendo a vantagem relativa de escrever depois daqueles autores, podendo avaliar o que, das técnicas e temas trabalhados por eles, seria

33 Veja-se, por exemplo, a explicitação do uso de galicismo na carta a Mário de I3 de outubro de I924: "Bem sei o que sucede: vivemos balotados (que galicismo gostoso! É como maquilhada) entre as duas atitudes”. Apud MORAES, Marcos Antonio de (Org.), op. cit., p. I38.

34 Carta de Manuel Bandeira a Mário de Andrade, 3 de janeiro de I925, apud MORAES, Marcos Antonio de (Org.), op. cit., p. I75.

35 CASTRO ROCHA, João Cezar de; JOBIM, José Luís. From Europe to Latin American. Journal of World Literature, v. I, 20I6, p. 52-62.

36 HUERTA, Efraín. Poesía completa. Ciudad de México: Fondo de Cultura Económica, 2004, p. 326. 
relevante ou não para a sua obra, Bandeira pôde escolher o que achava melhor, dentro das circunstâncias, incorporando, alterando, criticando, recusando o que quisesse.

Em Mário de Andrade, também encontramos a crítica ao uso da "influência" como critério para avaliação literária, muito presente nos anos I920, inclusive na mente de autores modernistas. Já apontamos antes ${ }^{37}$ isso na correspondência entre ele e Drummond, nos anos I920, na qual o poeta mineiro, ingenuamente, declara ainda estar na fase de formação, como escritor, portanto muito sujeito a influência. Mário responde:

Agora raciocinemos no que você fala da minha influência sobre você. Em última análise tudo é influência neste mundo. Cada indivíduo é fruto de alguma coisa. Agora, tem influências boas e influências más. Além do mais se tem que distinguir entre o que é influência e o que é revelação da gente própria. Muitas vezes um livro revela pra gente um lado nosso ainda desconhecido. Lado, tendência, processo de expressão, tudo. $\mathrm{O}$ livro não faz que apressar a apropriação do que é da gente ${ }^{38}$.

Sob a designação de influência, está em jogo aqui o conceito de apropriação, que na sua versão mais ingênua supõe que o "influenciado" se apropria de obra do "influenciador" nos termos em que esta foi elaborada anteriormente, acrescentando a isso uma atribuição de inferioridade ao "influenciado" e a presunção de que a posição de inferioridade só vai se alterar quando o "influenciado" ganhar "autonomia", ou seja, não for mais influenciado por ninguém. Como já dissemos antes ${ }^{39}$, essa ingenuidade conceitual, além de ser utilizada para julgar a relação entre autores, também foi utilizada para julgar a relação entre literaturas nacionais, com todos os problemas que isso acarreta. Mário, ao escrever que "tudo é influência neste mundo" e que "cada indivíduo é fruto de alguma coisa", expõe consequências tanto de nível mais "individual" quanto de mais "genérico", por assim dizer. Em nível mais "individual”, ele tranquiliza Drummond não só em relação às preocupações dele com a "influência" de Mário, mas também em relação a quaisquer outras fontes de influência, ao sugerir que, de fato, como os indivíduos não bastam a si próprios, pois inevitavelmente pagam tributo ao contexto em que se inserem, são sempre "fruto de alguma coisa" - e isto não seria nenhum demérito, porque, se "em última análise tudo é influência neste mundo", então haveria uma disseminação generalizada de apropriações, trocas e transferências literárias em sistemas culturais, que estaria longe de se esgotar no nível de uma relação entre dois poetas:

Dentro das tendências mais contemporâneas de teorização sobre trocas e transferências culturais, a afirmativa de Mário poderia corroborar a perspectiva de que as

37 JOBIM, José Luís. O original e o próprio, o derivado e o impróprio: Mário de Andrade e as trocas e transferências literárias e culturais. In: Literatura e cultura: do nacional ao transnacional. Rio de Janeiro:

Editora da Universidade do Estado do Rio de Janeiro, 20I3, p. I5I-I66.

38 Carta de Mário de Andrade a Carlos Drummond de Andrade apud SANTIAGO, Silviano (Org.), op. cit., p. II6 (grifos nossos).

39 JOBIM, José Luís. O original e o próprio, o derivado e o impróprio..., op. cit. 
apropriações devem ser entendidas também pelo viés dos interesses que presidiram o próprio ato histórico e determinado de apropriação, e não apenas pelo sentido que supostamente, no seu contexto de origem, teria o elemento que foi apropriado. Isto explicaria a significação de "apropriar-se do que é da gente": o poeta apropria-se de elementos que transformam-se em seus, porque foram escolhidos a partir de seus interesses e porque ganham contexto e sentido diferente na sua obra - transmutando-se em outra coisa, diferente da que era, no contexto em que se inseria antes. A "revelação da gente própria”, que pode surgir de uma leitura, é exatamente esta captação do que, na obra do outro, pode ser incorporado ao projeto próprio do leitor, por relacionar-se com o projeto de quem a lê, e iluminar um sentido que já estava presente na vida do leitor, mas que ainda não havia ganhado uma verbalização que o configurasse de forma a tornar-se claro para este leitor, desvelando o próprio dele através do texto alheio ${ }^{40}$.

No que diz respeito à contextualização mais ampla de seu próprio trabalho, Mário tinha claro para si que, da leitura dos autores contemporâneos europeus ou de seus antecedentes imediatos, o que aparecia na obra dele não eram exatamente traços específicos das obras europeias, mas vestígios do contexto histórico comum a todos, e que Mário chama de modernidade. Por isso, ele escreve, em carta a Manuel Bandeira, de 6 de junho de I922, apontando o equívoco de certos críticos, ao atribuírem a ele a imitação de escritores europeus: "Sei que dizem de mim que imito Cocteau e Papini. [...] É verdade que movo como eles as águas da modernidade. Isso não é imitar: é seguir o espírito duma época”ㄷ. E Bandeira responde:

Claro que não lhe deve importar que o deem por imitador de Cocteau e Papini, deste e daquele. Já tenho visto essa maneira, forma, estrutura, ou que melhor nome tenha, em vários poetas franceses, italianos. Em português agora você. Você é imitador deles como todo o poeta que escreve em metro regular é imitador de todos os poetas que o precederam e que foram por ele assimilados. Um poema realmente digno desse nome implica em matéria de sensibilidade e de técnica a assimilação de todo o passado e, a mais, alguma coisa que balbucia - e é a contribuição ingênua do poeta ${ }^{42}$.

Outro escritor do círculo modernista a dar importância ao tema é Oswald de Andrade, como veremos a seguir.

40 Ibidem.

4I Carta de Mário de Andrade a Manuel Bandeira, 6 de junho de I922, apud MORAES, Marcos Antonio de (Org.), op. cit., p. 62. Veja-se outro exemplo de argumentação de Mário de Andrade, na carta a Prudente de Moraes, neto, escrita em 3/10/I925: "De mim já se falou que sou futurista, que sou desvairista, que sou impressionista, que sou clássico e que sou romântico. É verdade que tenho sintomas e qualidades de tudo isso. Porém é questão de fim de receita: Dissolva-se tudo isso no século vinte e agita-se. Que que dá? Dá moderno. Estou convencido que sou do meu tempo". Apud KOIFMAN, Georgina, op. cit., p. I22-I23.

42 Carta de Manuel Bandeira a Mário de Andrade, 3 de julho de I922, apud MORAES, Marcos Antonio de (Org.), op. cit., p. 65. 


\section{O CaSo OsWald de ANDRADE}

Para Oswald de Andrade, as viagens à França, onde edita Pau Brasil, são decisivas para ele "descobrir" o Brasil. De fato, o livro termina com o poema "Contrabando", falando do retorno ao porto de Santos:

Os alfandegueiros de Santos

Examinaram minhas malas

Minhas roupas

Mas se esqueceram de ver

Que eu trazia no coração

Uma saudade feliz

De Paris ${ }^{43}$.

Aracy Amaral já mostrou a conexão entre Oswald de Andrade e o meio artístico parisiense quando ele fez sua segunda viagem à Europa, em I923, acompanhado da pintora Tarsila do Amaral:

Juntos fariam uma verdadeira "descoberta do Brasil” desde Paris, ele reescrevendo Memórias sentimentais de João Miramar já em contatos parisienses que fariam o texto definitivo ser um contraste com aquele publicado em capítulos no Brasil, e Tarsila já pintando “A Negra”, e “Caipirinha”. O fim de I923, já em contato com Cendrars e através dele com artistas, literatos e músicos, tipo Léger, Supervielle, Cocteau, Valery-Larbaud, Gleizes etc., coroa um ano de crescimento artístico no sentido de verdadeira absorção de "modernidade" tanto por parte de Oswald como de Tarsila. Ele já distante quilômetros, como ela, de seus poemas franceses publicados em I920, e ela igualmente longe de suas pinturas iniciadas após treinamento, em I920, na Academia Julien, de Paris ${ }^{44}$.

Provavelmente Oswald também leu a revista de vanguarda Cannibale, editada por Francis Picabia, que teve apenas dois números publicados, mas foi muito marcante não só para os dadaístas, como também para as vanguardas parisienses em geral. Foi no segundo número de Cannibale que G. Ribemont-Dessaignes, respondendo à acusação de que o Dadaísmo era alemão, produziu uma argumentação fora dos parâmetros então vigentes - lembremo-nos de que a Primeira Guerra Mundial, colocando em campos opostos os franceses e os alemães, ainda era um evento recente, em 25 de maio de I920, quando foi publicada essa revista. Vejamos, então, a argumentação de G. Ribemont-Dessaignes naquela revista:

43 ANDRADE, Oswald de. Contrabando. In: Pau Brasil. Paris: Sans Pareil, I925.

44 AMARAL, Aracy. Oswald de Andrade e as artes plásticas no Modernismo dos anos 20. Revista do Instituto de Estudos Brasileiros, n. 33, I992, p. 68-75. p. 7I. Disponível em: <www.revistas.usp.br/rieb/article/ viewFile/7047I/73245>. Acesso em: 25 jul. 2017. 
Toutes les médailles et décorations de la gloire française sont made in Germany ou made in Italy et autres lieux, et n'ont été dorées qu'en France. Les périodes classiques sont issues de Grèce, d'Italie, de Flandre, d'Arabie, de Chine. La période moderne vient d'Angleterre, de Scandinavie, d'Allemagne et tout récemment d'Afrique, de Polynésie, du Japon e d'Espagne.[...] La vertu française est précisément d'absorber sans em mourir um tas de produits différents et de les rendre assemblés avec un odeur telle qu'on ne peut se tromper dans le monde entier sur l'origine de cette synthèse, et qu'on dit de l'Amérique à la Tchéco-Slovaquie: "Comme ćest exquis. Voilá le goût français!"45.

Quero aqui chamar a atenção do leitor para alguns aspectos importantes desse artigo, intitulado "Dadaland”. O primeiro é que o articulista vai na mesma direção de sentido da famosa conferência de Renan em I882, quando aquele maître à penser produziu uma argumentação no sentido de justificar a identidade francesa não como algo "puro", adquirido como herança, consolidado e enraizado, mas como fruto de decisões tomadas por uma população que não era homogênea nem étnica nem linguisticamente. Ribemont-Dessaignes, ao alegar que mesmo as medalhas para celebrar a glória da França eram apenas pintadas de dourado lá, mas feitas em outros lugares, incluindo a Alemanha, torna inválidos os argumentos dos "puristas", e valoriza exatamente o oposto - ou seja, a virtude francesa de absorver e incorporar o outro, produzindo uma síntese original que pode ser reconhecida como francesa.

O segundo aspecto importante a ressaltar é que, em I928, no seu famosíssimo Manifesto antropófago, Oswald de Andrade também vai colocar, de forma telegráfica, referências ao Brasil como lugar de acolhimento e integração, mas que recusa a importação de "consciência enlatada", ou seja, recusa internalizar modos de pensar fechados, impermeáveis à transformação no contato com a realidade do Novo Mundo. A deglutição antropofágica do outro, transformando o que se comeu em nova energia para o antropófago - mas sem nenhuma pretensão à síntese hegeliana, proposta por Ribemont-Dessaignes -, é a metáfora do acolhimento e da integração transformativa desse outro no organismo que o processa.

Como já escrevemos ${ }^{46}$, embora Oswald cite explicitamente uma série de nomes da cultura francesa, como Montaigne, Rousseau, Lévy-Bruhl, ele não incorpora acriticamente o que disseram. Se o próprio Montaigne considerava que a medida do que pensamos sobre os outros são os costumes e as opiniões do lugar em que nos encontramos, os critérios de verdade e da razão formulados em países europeus e transferidos para as Américas teriam também de sofrer modificações no seu novo contexto. Oswald, assim, recusa a reiteração absoluta daquilo que se recebeu. Ao declarar-se "Contra todos os importadores de consciência enlatada”77, explicita posição análoga à do ensaísta uruguaio Enrique Rodó, que desmente a tese de que

45 RIBEMONT-DESSAIGNES, G. Dadaland. Cannibale, 2, I920, p. 8. Disponível em: <sdrc.lib.uiowa.edu/dada/ cannibale/2/images/o8.pdf>. Acesso em: 22 jul. 2017.

46 JOBIM, José Luís. Cannibalism as cultural appropriation: from caliban to the Cannibalist Manifesto. In: (Ed.). Literary and cultural circulation. Oxford: Peter Lang, 20I7, p. 35I-368.

47 ANDRADE, Oswald de. Manifesto antropófago. (I928). In: ROCHA, João Cezar de Castro (Org.). Antropofagia hoje? São Paulo: É Realizações, 20II, p. 49-54. 
é possível transplantar ideias, costumes e instituições tais como existiam em sua origem ${ }^{48}$.

Também já assinalamos ${ }^{49}$ que, no capítulo Des Cannibales dos seus Essais, Montaigne faz menção ao canto de um prisioneiro que será devorado e diz aos seus captores que, ao comê-lo, estarão comendo os pais e avós deles, que tinham sido devorados antes pelo prisioneiro. Assim, a antropofagia também se refere a uma filiação, em que na carne do devorado está o gosto da família do devorador. Para Oswald, o Brasil Caraíba deglutiu a Europa, transformando-a em outra coisa, em seu estômago, diferente do que existia no velho continente.

Para terminar nossa argumentação aqui, então, faremos duas últimas observações. A primeira é que, a rigor, em vez de falarmos de relação cultural entre a França e o Brasil, nos anos 20 do século passado, deveríamos falar de relação entre Paris e a intelectualidade brasileira - o próprio Drummond, como vimos antes, declarou que queria ter nascido em Paris (não na França). No entanto, é importante acrescentar que aquela cidade não era referência fortíssima apenas para os escritores brasileiros, pois naquele período já era uma referência cultural internacional.

A segunda é que, embora ainda houvesse manifestações mais ingênuas de filiação francófila no Brasil, como a de Drummond, na carta citada, já se elaborava toda uma conceitualização sobre como os elementos estrangeiros serão processados e transformados no Brasil. Recuperar as discussões travadas nos anos I920, principalmente através das cartas trocadas pelos autores modernistas, pode ser muito importante para lançar luz sobre aspectos pouco esclarecidos das relações literárias franco-brasileiras.

\section{SOBRE O AUTOR}

JOSÉ LUÍS JOBIM é professor de Teoria da Literatura, Literatura Comparada e Literatura Brasileira e coordenador do Programa de Pós-Graduação em Estudos da Literatura da Universidade Federal Fluminense (UFF).

E-mail: jjobim@id.uff.br

\footnotetext{
48 "El engaño de los que piensan haber reproducido en lo esencial el carácter de una colectividad humana, las fuerzas vivas de su espíritu, y con ellos el secreto de sus triunfos y su prosperidad, reproduciendo exactamente el mecanismo de sus instituciones y las formas exteriores de sus costumbres, hace pensar en la ilusión de los principiantes candorosos que se imaginan haberse apoderado del genio del maestro cuando han copiado las formas de su estilo o sus procedimientos de composición”. RODÓ, José Enrique. Ariel. Valencia: Editorial Cervantes, I920. Release Date: October 5, 2007 [EBook \#22899]. Disponível em: <www.gutenberg.org/files/22899/22899h/22899-h.htm>. Acesso em: 2 jun. 2017.
}

49 JOBIM, José Luís. Cannibalism as cultural appropriation..., op. cit. 


\section{REFERÊNCIAS BIBLIOGRÁFICAS}

AMARAL, Aracy. Oswald de Andrade e as artes plásticas no Modernismo dos anos 20. Revista do Instituto de Estudos Brasileiros, n. 33, I992, p. 68-75. Disponível em: <www.revistas.usp.br/rieb/article/viewFile/7047I/73245>. Acesso em: 25 jul. 2017.

ANDRADE, Mário de. Poesias completas. V. 2. São Paulo: Martins, I980, p. 242.

ANDRADE, Oswald de. Contrabando. In: . Pau Brasil. Paris: Sans Pareil, I925.

. Manifesto antropófago. (I928). In: ROCHA, João Cezar de Castro (Org.). Antropofagia hoje?. São Paulo: É Realizações, 20II, p. 49-54.

BANDEIRA, Manuel. Poesia e prosa. V. I. Rio de Janeiro: José Aguilar, I958.

CANDIDO, Antonio. Lembrança de Mário de Andrade. In: . O observador literário. (I ${ }^{\mathrm{a}}$ ed., I959). 3. ed. rev. e ampliada. Rio de Janeiro: Ouro Sobre Azul, 2004, p. 9I-95.

CASTRO ROCHA, João Cezar de; JOBIM, José Luís. From Europe to Latin American. Journal of World Literature, v. I, 20I6, p. 52-62.

HUERTA, Efraín. Poesía completa. Ciudad de México: Fondo de Cultura Económica, 2004.

JOBIM, José Luís. Formas da teoria. Rio de Janeiro: Caetés, 2003.

. O original e o próprio, o derivado e o impróprio: Mário de Andrade e as trocas e transferências literárias e culturais. In: . Literatura e cultura: do nacional ao transnacional. Rio de Janeiro: Editora da Universidade do Estado do Rio de Janeiro, 20I3, p. I5I-I66.

. Cannibalism as cultural appropriation: from caliban to the Cannibalist Manifesto. In: (Ed.). Literary and cultural circulation. Oxford: Peter Lang, 20I7, p. 35I-368.

KOIFMAN, Georgina. Cartas de Mário de Andrade a Prudente de Moraes, neto (1924/36). Rio de Janeiro: Nova Fronteira, I985.

LUIZ, D. Fr. Francisco de S. Glossário das palavras e frases da língua francesa, que por descuido, ignorância ou necessidade se tem introduzido na locução portuguesa moderna. Lisboa: Tipografia da Academia Real das Ciências, I827. Disponível em: <sebinaol.unior.it/sebina/repository/catalogazione/documenti/ Glossario\%2odas\%2opalavras\%20(397349).pdf >. Acesso em: 24 jul. 2017.

MARIANI, Bethania \& JOBIM, José Luís. National language and postcolonial Brasil. Revista da ANPOLL, 20, 2006, p. II-36. Disponível em: <revistadaanpoll.emnuvens.com.br/revista/article/view/473/482〉. Acesso em: 24 jul. 2017.

MORAES, Marcos Antonio de. Correspondência - Mário de Andrade e Manuel Bandeira. São Paulo: Editora da Universidade de São Paulo, 2000. 736 p.

MOREIRA, Paulo Vaz. Quando a América se torna pela primeira vez latina. In: JOBIM, José Luís. A circulação literária e cultural. Oxford: Peter Lang, 20I7, p. I53-I80.

NABUCO, Joaquim. Minha formação. [I90o]. Disponível em: <www.iphi.org.br/sites/filosofia_brasil/ Joaquim_Nabuco_-_Minha_Forma\%C3\%A7ao.pdf $>$. Acesso em: 24 jul. 2017.

RENAN, Ernest. Qu'est-ce qu'une nation? Paris: Calmann Lévy, I882. Disponível em: <fr.wikisource.org/ wiki/Qu\%E2\%80\%99est-ce_qu\%E2\%80\%99une_nation_\%3F>. Acesso em: 24 jul. 2017.

RIBEMONT-DESSAIGNES, G. Dadaland. Cannibale, 2, I920, p. 8. Disponível em: <sdrc.lib.uiowa.edu/dada/ cannibale/2/images/o8.pdf >. Acesso em: 22 jul. 2017.

ROCCA, Pablo. Os contrabandistas: tensões e fundamentos da primeira circulação de Machado de Assis no Rio da Prata. In: SECCHIN, Antonio Carlos; BASTOS, Dau; JOBIM, José Luís (Org.). Machado de Assis: novas perspectivas sobre a obra e o autor no centenário de sua morte. Niterói: Editora da Universidade Federal Fluminense; Rio de Janeiro: De Letras, 2008, p. I4I-I60.

RODÓ, José Enrique. Ariel. Valencia: Editorial Cervantes, I920. Release Date: October 5, 2007 [EBook 
\#22899]. Disponível em: <www.gutenberg.org/files/22899/22899h/22899-h.htm〉. Acesso em: 2 jun. 2017.

SANTIAGO, Silviano (Org.). Carlos e Mário. Correspondência de Carlos Drummond de Andrade e Mário de Andrade. Rio de Janeiro: Bem-te-vi, 2002. 6I8 p.

SISKIND, Mariano. Dislocating France; world literature, global modernism and cosmopolitan distance. Journal of World Literature, v. 2, issue I, 20I7, p. 47-62. p. 54.

VERISSIMO, José. Letras hispano-americanas. In: . Homens e coisas estrangeiras, I899-I908. Prefácio de João Alexandre Barbosa. Rio de Janeiro: Academia Brasileira de Letras/Topbooks, 2003, p. 469-478. 